\title{
A Moderated Mediation Model of Factors Influencing Intention to Adopt Cryptocurrency among University Students
}

\author{
Saher Zeast Hasan $\mathbb{D}^{1},{ }^{1}$ Huma Ayub $\mathbb{D}^{2},{ }^{2}$ Abida Ellahi $\mathbb{D}^{3},{ }^{3}$ and Mahnoor Saleem $\mathbb{D}^{2}$ \\ ${ }^{1}$ Bahria University, Islamabad, Pakistan \\ ${ }^{2}$ Department of Business Administration, Fatima Jinnah Women University, Pakistan \\ ${ }^{3}$ Department of Management Sciences, Abbottabad University of Science \& Technology, Pakistan \\ Correspondence should be addressed to Huma Ayub; huma_ayub@fjwu.edu.pk
}

Received 22 October 2021; Revised 15 December 2021; Accepted 6 January 2022; Published 10 February 2022

Academic Editor: Zheng Yan

Copyright (c) 2022 Saher Zeast Hasan et al. This is an open access article distributed under the Creative Commons Attribution License, which permits unrestricted use, distribution, and reproduction in any medium, provided the original work is properly cited.

\begin{abstract}
The goal of this study is to find out what people think about cryptocurrencies and how they feel about it. The study used a questionnaire to assess the factors that influence people's willingness to accept cryptocurrency. The study used a pretest, posttest quantitative analysis to determine the level of awareness among users in the first phase. In the second step, information regarding the conceptual framework was gathered using a survey approach. For the study, 350 university students were chosen as the sample size. Hypotheses about the significant effects of perceived benefits, perceived risks, perceived value, and structural provisions on behavioral intention to adopt cryptocurrency were accepted, while hypotheses about social effects, moderating effect of self-efficacy and personal innovativeness as well as the mediator attitudes towards using cryptocurrency, were not statistically proven. The tested model and resultant findings have brought many managerial and theoretical implications for enhancing the intention to adopt cryptocurrency.
\end{abstract}

\section{Introduction}

The current digital era has brought some key changes in the global economic situation as well as in the context of traditional financial operations. In the current global and economic context, blockchain technology has revolutionized individual interactions and financial operations such as investment, trading, and online payments. Moreover, this blockchain also fulfills the requirements of a demanding regulatory tool for a newly emerged category of currency, i.e., virtual currency to regulate it securely through decentralization, cryptography, and public circulation of its content [1]. It works like a computer that is connected to a whole network of users and has a copy of all transactions made by the users (Sudzina \& Pavlicek, [2]).

One of the most renowned marvels of this technology is cryptocurrency. There are quite a lot of types of cryptocurrencies around the globe having their specific features [3]. The first-ever cryptocurrency is bitcoin proposed and used in 2009 by Satoshi Nakamoto [4]. Currently (as of March 2020), among numerous cryptocurrencies being traded on global exchanges, bitcoin has the highest market capitalization [5]. Churchill [6] proposed that the unique features of it (like anonymity, decentralization, and control) may affect the perceptions of designers and users about future cryptocurrency transactions.

World Economic Forum report reveals that $10 \%$ of the global gross domestic product (GDP) will be kept through blockchain technology by the year 2025 [7]. Cryptocurrencies have both positive and negative characteristics as some are beneficial but at the same time, some characteristics (anonymity, volatility) can lead to various problems for individuals (Schaupp \& Festa, [8]).

1.1. Cryptocurrency in Pakistan. In Pakistan, cryptocurrencies are getting fame. Pakcoin was the first cryptocurrency launched in Pakistan in 2015. However, in 2018, when cryptocurrencies were uprising in the financial technology world, 
the usage of digital currencies was banned by the Federal Board of Revenue and State Bank of Pakistan [9]. SBP [9] argued that although in Pakistan, cryptocurrencies are around for a considerable amount of time, however, currently, people are not well aware of it. Meanwhile, cryptocurrency is not regulated; therefore, regulatory concerns may emerge.

Since 2009, many innovations have been witnessed in payment systems such as Easypaisa. The fame and evolution of these innovations recommend that there is enough potential for the growth of cryptocurrencies in Pakistan [10]. The benefits of cryptocurrencies including free mobility of finances around the globe and income opportunities can prove to be helpful in the economic growth of Pakistan but at the same time, the threats cannot be neglected [11]. However, along with these cons, cryptocurrency can boost the economy of Pakistan due to its benefits. This technological phenomenon is widely used around the globe, and Pakistan can also get benefits from its adoption with good governance and regulations [10].

Therefore, this study is conducted to find out the intention of individuals to adopt cryptocurrency and also to explore the factors that affect their intention to adopt it. Several studies measured the intention of individuals to use cryptocurrency in different contexts (Alqaryouti, Siyam, Alkashri, \& Shaalan, [12]; Abramova \& Böhme, [13]; Gazali, Ismail, \& Amboala, [14]; [15]); however, there is a lack of research exploring the factors that may affect individuals' behavioral intention to use cryptocurrency in Pakistan. Thus, the study at hand purposes to explore the factors that affect the behavioral intention of individuals and also their awareness about cryptocurrency in Pakistan.

The study also has the objective of empirically testing a conceptual model developed by Esmaeilzadeh, Subramanian, and Cousins [16]. The conceptual model is based on UTAUT and utility theory and presents a comprehensive view of constructs like facilitating conditions, social effects, and perceived risks as well as perceived benefits in the context of cryptocurrency. With this aspect, the current research has a new contribution that it provides insights into users' intentions and attitudes towards using cryptocurrencies.

\section{Literature Review}

2.1. Cryptocurrency. Cryptocurrency is a type of digital currency that uses the technique of cryptography and blockchain to secure financial transactions (Sudzina \& Pavlicek, [2]). This is one of the novel technology around the globe (Bibi, Hussain, \& Faisal, [17]). Unlike fiat currencies, cryptocurrencies are decentralized, as they are not issued or backed by any regulatory body or government. It provides anonymity, low cost, and quick and transparent transactions by using blockchain technology [11] which is an innovative technology that has lifted the whole pattern of computer applications and traditional methods of financial transactions during the last decade. Other than financial and money markets, blockchain is also an emerging technology in vertical industries (Sarwar, Nisar, \& Khan, [18]). It is a decentralized network that contains confidential data with strong privacy and security. Cryptocurrency is the first one of the many applications built by using blockchain technology. This technology provides the necessary rigorous regulatory frameworks to the newly emerged type of currency, i.e., cryptocurrency, by incorporating innovative vital principles such as cryptography, public distribution of contents through public ledgers, and decentralization [1].

Cryptocurrency is a relatively novel, emerging, and controversial technology, particularly in Pakistan. Shoaib et al. [19] introduced the idea and necessary modules of the Official Digital Currency System (ODCS) in the context of Pakistan. The study suggested the issuance and governance of digital currency by the state bank of the country. This suggested idea of ODC is very much similar to cryptocurrency, as it is also virtual in nature. Among numerous cryptocurrencies being traded on global exchanges, bitcoin has the highest market capitalization [5]. It is a revolutionary sort of currency in the new global financial system which requires regularization by financial institutions and governments that raise knowledge and trust in cryptocurrency adoption among citizens [20].

Alshamsi and Andras [21] investigated users' experiences and perceptions of a novel digital payment system that is not renowned among them. Abramova and Böhme [13] found that bitcoin is impotent to attract a large number of the audience because individuals have considerable concerns related to cryptocurrencies including unstable value, hacking of users' or system providers' devices, financial losses due to operational risk, and the lack of users' safety. All of these researches looked into distinct characteristics of various cryptocurrency forms, but none of them provided a comprehensive model of all factors that influence cryptocurrency adoption.

2.2. Theoretical Model. Esmaeilzadeh et al. [16] proposed a qualitative model by extending utility theory and unified theory of acceptance and use of technology (UTAUT). The unified theory of acceptance and use of technology model (UTAUT) was designed by Venkatesh et al. [22], and it is well known as a reputable tool to determine the use and acceptance of innovative and advanced technologies [23]. Lee et al. [23] tested the applicability of the UTAUT model in predicting users' intentions to accept blockchain technology in the Northeast region of the United States. The findings revealed that blockchain acceptance has a lot of room for growth, especially among IT professionals and younger generations who might be early adopters. So, this theory is applicable for this research to determine the intention of individuals to adopt cryptocurrency affected by social influence and facilitating conditions.

The current study is based on the theoretical model proposed by Esmaeilzadeh et al. [16]. The model included positive utilities (perceived benefits) and negative utilities (perceived risks), perceived value, structural provisions, personality traits (innovativeness and self-efficacy), attitude, and intention to adopt bitcoin. Based on utility theory and unified theory of acceptance and use of technology (UTAU $\mathrm{T}$ ), the model provides a comprehensive overview of factors that can affect bitcoin, i.e., cryptocurrency adoption. 
According to Esmaeilzadeh et al. [16], "The proposed model can serve as a foundation for future studies addressing factors shaping individuals' Bitcoin adoption decisions. Further research is required to empirically test the model to articulate Bitcoin adoption at the individual level"(p.1). Therefore, this research has adopted this moderated mediation model to measure the adoption intention of people towards cryptocurrency in the context of Pakistan, a developing country.

\section{Theoretical Model Variables}

3.1. Behavioral Intention to Adopt Cryptocurrency. Contemporary literature shows a vast amount of published research work on the perceptions of cryptocurrency users in different countries' contexts, but in Pakistan, a developing country, there is a restricted number of published books and academic researches related to cryptocurrency, fintech, and blockchain area and particularly about the perceptions of people to adopt them.

Chan et al. [24] observed the factors that affected the behavioral intention of Ipoh residents in Malaysia towards the adoption of cryptocurrency. Duma and Gligor [1] conducted another research on some of the students from the Babeș-Bolyai University (part of Gen Z). The study was concerned about the behavior and perceptions of these students about the Fintech area mainly blockchain technology and cryptocurrencies. Shahzad et al. [20] also researched to explore the key elements that affect the adoption of cryptocurrencies among the people of China. Chow et al. [25] proposed a model to inspect the determinants of cryptocurrency acceptance and usage intention, by combining cryptocurrency dimension with the constructs of unified theory of acceptance and use of technology 2 (UTAUT2). Arias-Oliva, Pelegrín-Borondo, and Matías-Clavero [26] used a technology acceptance theoretical framework to analyze the key determinants for the effective development of cryptocurrency from the viewpoint of consumers. Based on the findings of Arias-Oliva et al. [26], the overall intention to use cryptocurrencies was low among college-educated adults in Spain. However, in Ukraine, the vast majority of individuals are well aware and intended to use cryptocurrency [27]. Gazali et al. [14] suggest that generally the subjective norms, perceived benefits, and attitudes lead to the intention to invest in cryptocurrency. Nadeem et al. [28] found that individuals' intention to adopt bitcoin in China significantly increases if the technology is easy to use and understandable by individuals. Therefore, based on previous literature, behavioral intention has been taken as a main dependent variable in this study.

3.2. Perceived Benefits. Perceived benefit refers to the positive beliefs of an individual that the use of cryptocurrency will yield positive outcomes. It can be rationally assumed that people are varied in their views and perceptions about the benefits and risks of cryptocurrency [13]. Several studies have assessed the impacts of perceived benefits on an individual's behavioral intention to adopt cryptocurrency [12-15]; however, none of the studies assessed the impacts of perceived benefits on perceived value from cryptocurrency.

Esmaeilzadeh et al. [16], in their proposed model, included pseudonymity, universality, investment, ease of use, fast transaction, and low transaction cost as dimensions of perceived utilities (benefits). Perceived benefits of cryptocurrency by individuals will enhance its value, and it can significantly affect their decisions to adopt it. The findings of the research performed by Gazali et al. [14] suggested that perceived benefits affect the intention to invest in cryptocurrency. Walton and Johnston [29] also found that individuals' intention to use bitcoin in South Africa is directly influenced by perceived benefits. Based on the above discussion, the following hypothesis has been proposed:

H1 (a): Perceived benefits positively influence perceived value from cryptocurrency.

H1 (b): Perceived benefits positively influence behavioral intention to adopt cryptocurrency.

3.3. Perceived Risks. Perceived risk refers to negative consequences and uncertainty linked with the use of cryptocurrencies for online payments and transactions, perceived by users [13]. Although cryptocurrency is a new phenomenal currency and has a lot of features, however, it comes with many risks such as price instability, future legislation, ecommerce technical flaws, theft or loss, and exchange rate risk [14].

Literature shows numerous studies that have assessed the impacts of perceived risks on perceived usefulness [30] and individual's behavioral intention to adopt cryptocurrency $[13,24,26,31]$, with varying results, but no one assessed the impact of perceived risks on perceived value from cryptocurrency. The following dimensions of perceived risks are incorporated in this study: instability $[8,16,25,27$, 32-36], operational risk [37], technical flaws [16], lack of regulation $[8,13,20,38-41]$, and security losses [13, 27, 39].

Existing literature shows the significance of perceived risk in many contexts. Perceived risk negatively affects the intention to use cryptocurrencies in e-commerce [31]. The findings of the research conducted by Kazi and Mannan [42] revealed that customers' intention to adopt mobile banking services in Pakistan is negatively affected by perceived risk. In the cryptocurrency context, Chan et al. [24] found that perceived risk is one of the variables that significantly influence the behavioral intention towards cryptocurrency acceptance among Ipoh Residents. Similarly, Parashar and Rasiwala [43] found that if the perceived risks are reduced, then the individuals would be more interested in the adoption of cryptocurrency in Pune city of India. Therefore, it is proposed as follows:

H2 (a): Perceived risks negatively influence perceived value from cryptocurrency.

H2 (b): Perceived risks negatively influence behavioral intention to adopt cryptocurrency.

3.4. Perceived Value from Cryptocurrency. Perceived value is a tradeoff between perceived benefit and perceived risk or cost [44]. This study examined how variables associated with perceived risks and perceived benefits respond to perceived 
value in a user's causal relationship and what influence perceived value can have on attitude and behavioral intention of individuals to use cryptocurrency.

Many studies (e.g., [45]) refer to the assessment of intention to embrace a new technology as the benefits that may be gained from a given technology and how useful it is for individuals. As a result, it is envisaged that people's intentions to utilize blockchain technology would be influenced by their perceptions of its utility and enjoyment ([46] as cited in [47]).

Kim et al. [44] conducted a study in Singapore and found that perceived value has a significant influence on the intention of individuals to use mobile Internet. Similarly, Liu, Zhao, Chau, and Tang [48] researched in China and found a significant impact of perceived value on the behavioral intention of individuals to adopt mobile coupon applications. Furthermore, Pitchayadejanant [49] also revealed that there is a significant positive impact of perceived value on users' behavioral intention to use smartphones. Based on the above discussion, the following hypothesis has been proposed:

H3: Perceived value from cryptocurrency positively affects individuals' attitudes towards using cryptocurrency.

3.5. Social Effects. Social effects in this study refer to the influence of significant others (from the society) on intention to adopt cryptocurrency. Social norms (social influence) are one of the dimensions of social effects [16]. In literature, various studies show varying results of the impact of social factors on intention to use cryptocurrency. Some studies found the significant positive impacts of social factors on intention to use cryptocurrency $[8,15,24]$, whereas some studies found an insignificant role of social factors in the behavioral intention to use cryptocurrency (e.g. [26]).

In Pakistan's context, Kazi and Mannan [42] found a significant positive relationship between social influence and the adoption intention of mobile banking by customers. Moreover, Farah et al. [50] also found that social factors play an important role in enhancing customers' adoption intention of mobile banking. Generally, all decentralized currencies' adoption is affected by network effects because their benefits and value are associated with the number of users of that currency. Therefore, the social effects, particularly the role of subjective norms, are required to analyze the adoption and use of cryptocurrency [13]. Based on the above discussion, the following hypothesis has been proposed:

H4: Social effects positively affect individuals' behavioral intention to use cryptocurrency.

3.6. Structural Provision. Esmaeilzadeh et al. [16] proposed that other than the social effects resulting from the influence of society and the perceived benefits and risks associated with cryptocurrency's features, the structural provision also plays an important part in the intention to adopt cryptocurrency. The structural provision includes the necessities, facilitating conditions, and infrastructures available to update and support the process of adoption.

Cryptocurrency is decentralized; hence, it is not supported by any government, and there is no set of rules to be followed for cryptocurrency transactions; however, the necessary knowledge, advice, inquiries, and suggestions are provided through social media pages, virtual cryptocurrency communities, discussion forums, and cryptocurrency exchange websites [30]. Necessary resources required to make transactions are laptops, cell phones, or other electronic devices to download the open-source software which is easily accessible by the general public [51].

Literature shows that the accessibility of facilitating conditions plays a vital role in cryptocurrency acceptance as basic technical and financial knowledge is required to use cryptocurrency. The findings of research conducted by Arias-Oliva et al. [26] in Spain revealed that the second most important factor (the first one is performance expectancy) for a given cryptocurrency's success is facilitating conditions. Facilitating conditions also have a positive significant impact on behavioral intention and acceptance of cryptocurrency among Ipoh Residents in Malaysia [24]. In the context of Pakistan, no study examined the impact of a structural provision in cryptocurrency adoption. If a user senses that the feasibility risk, amount of time, and effort are high, the user may not be intended to use that technology [23]. Based on the above discussion, the following hypothesis has been proposed:

H5: Structural provisions positively affect individuals' behavioral intention to adopt cryptocurrency.

3.7. Personality Traits (Personal Innovativeness and SelfEfficacy) as Moderating Variables. Personality traits are another factor affecting the intention of individuals to adopt cryptocurrency. Sudzina and Pavlicek [2] found that personality traits positively influence the usage of cryptocurrencies in the Czech Republic. This study incorporates two dimensions for personality traits as follows: self-efficacy [16, 52-54] and personal innovativeness [47, 55]. Literature shows various studies that measured the direct impact of personality traits on usage intention by taking one of its dimensions as constructs $[2,53]$ but its moderating role in the context of cryptocurrency has not been assessed. However, Esmaeilzadeh et al. [16] proposed moderating effect of personal innovativeness and self-efficacy.

According to previous researchers, e.g., ([56, 57], personal innovativeness is defined as a person's belief that he or herself is favorably disposed to employ innovative and novel technology. Because they have more favorable ideas about technology use, those with a higher risk tolerance are more willing to try out a new technology [58]. Abbasi et al. [59] have found personal innovativeness as a significant moderator between intention to use cryptocurrency and perceived value. According to them, "users who are extra innovative will try and adopt cryptocurrency usage as new technology in their daily lives, even when they do not perceive the value to be high (e.g., price value)" (p.8). Nazifi et al. [60] also hypothesized that "consumer innovativeness moderates the effectiveness of crypto-compensation such that the positive impact of crypto-compensation on recovery satisfaction is stronger (weaker) among consumers with a higher (lower) level of innovativeness" (p.11). 
Self-efficacy is an individual's belief in his ability to perform a task. Rogers [18] observed that innovation selfefficacy is a quality that is variable at an individual level and decidedly impacts the acknowledgment of new technologies and that self-efficacy has a positive relationship with the adoption of new technologies. This indicates that individuals with high technology self-efficacy view utilizing new technology generally as less troublesome. Therefore, individuals having high self-efficacy would be more willing to adopt cryptocurrency. Lee [61] studied digital technology self-efficacy as a moderator between fintech usage intention and digital technostress. Based on the above discussion, the following hypotheses have been proposed:

H6 (a): Self-efficacy positively moderates the relationships between attitudes towards using cryptocurrency and behavioral intention to adopt cryptocurrency.

H6 (b): Personal innovativeness positively moderates the relationships between attitudes towards using cryptocurrency and behavioral intention to adopt cryptocurrency.

3.8. Attitudes towards Using Cryptocurrency. Attitude is individual's assessment based on a set of beliefs (positive and negative feelings) about a particular behavior or an object [62]. The combination of beliefs about certain behavior and then its evaluation leads to a certain attitude towards using that behavior. If a person believes that cryptocurrency transactions are risky, the intention to adopt them will be lower. On the other hand, if a person believes that cryptocurrency transactions are not risky, the intention to adopt them will be higher relatively [20].

Literature shows some studies that evaluated the direct impact of attitude on an individual's intention to use cryptocurrency $[15,20]$ and intention to use e-shopping [63] but there is a lack of studies that assessed the mediating role of attitude in the context of cryptocurrency. However, Esmaeilzadeh et al. [16] proposed its mediating effect in their conceptual model. Walton and Johnston [15] explored factors that play a role in bitcoin adoption and found a large significant positive impact of attitude on individuals' behavioral intention in South Africa. Similarly, Schaupp and Festa [20] also found a significant relationship between attitude and behavioral intention to use cryptocurrency. Mosavi and Ghaedi [63] also found a positive impact of attitude on behavioral intention to use e-shopping services. In Pakistan, there is a lack of research in the cryptocurrency context; however, Mazhar et al. [64] found that attitude positively affects the behavioral intention of customers to adopt Internet or mobile banking in Pakistan. Based on the above discussion, the following hypotheses have been proposed:

H7 (a): Attitudes towards using cryptocurrency mediates the relationship between the perceived value from cryptocurrency and individuals' behavioral intention to adopt cryptocurrency with a moderating role of self-efficacy.

$H 7$ (b): Attitudes towards using cryptocurrency mediates the relationship between the perceived value from cryptocurrency and individuals' behavioral intention to adopt cryptocurrency with a moderating role of personal innovativeness.

The conceptual model is given below in Figure 1.

\section{Method}

4.1. Sample and Procedure. This study utilized a quantitative-based research method to achieve the aim and objectives of research. The target population of this study was university students in Pakistan. The current generation of university students in Pakistan was focused because they are mainly a part of Generation $\mathrm{Z}$ also known as iGen or Gen Tech. As evident from the research of Khan, Ilyas, and Rehman [65], members of Gen Z have high daily internet usage. A total of 356 responses were obtained for this study, with 6 being removed due to incomplete information provided, leaving 350 relevant responses. Convenient sampling technique was used because it is convenient, cost efficient, and easy.

As cryptocurrency is not widely used in the country, there was a possibility that if a survey was done directly, participants would be unable to communicate their true feelings about it. As a result, participants were first given a video on the cryptocurrency, and a pre- and posttest was administered to assess the effectiveness of video showcasing. This method was effective in reducing the risk of study participants becoming unaware. The pretest and posttest were used to assess respondents' intentions to embrace cryptocurrency before and after becoming aware of it, as cryptocurrency ignorance was one of the grounds for it being outlawed in Pakistan [11].

Before showing the video, the participants were asked to fill the questionnaire. Their responses were recorded, then they were shown a short informative video related to the cryptocurrency. The video simply explained what cryptocurrency is, how it works, its unique features, and the information about constructs used in this research. After the video, the participants were again asked to fill the same questionnaire. The data was analyzed using SPSS to measure the difference between pre- and postvideo opinions of participants. A prior consent was taken from the participants to participate in the study. Hence, their participation was voluntary.

4.2. Measures. The primary data for this research was collected through an online structured questionnaire. The questionnaire was based on a five-point Likert scale and was distributed through Google survey as well as many other social media platforms like Linked-In, WhatsApp, etc. The primary data was collected during the months of April to July 2020. Table 1 contains the information of scale items and their source from previous literature.

4.3. Data Analysis. After the data collection, statistical analysis was performed such as descriptive and inferential analysis by using SPSS (V.22.0). The descriptive analysis included frequency, Cronbach's Alpha, and Pearson correlation. The inferential analysis included hypothesis testing through appropriate relevant statistical tests.

\section{Results}

5.1. Demographic Profile. As shown in Table 2, the sample of this study is mainly composed of male respondents, i.e., 197 making $56.3 \%$ of the total participants, while female 


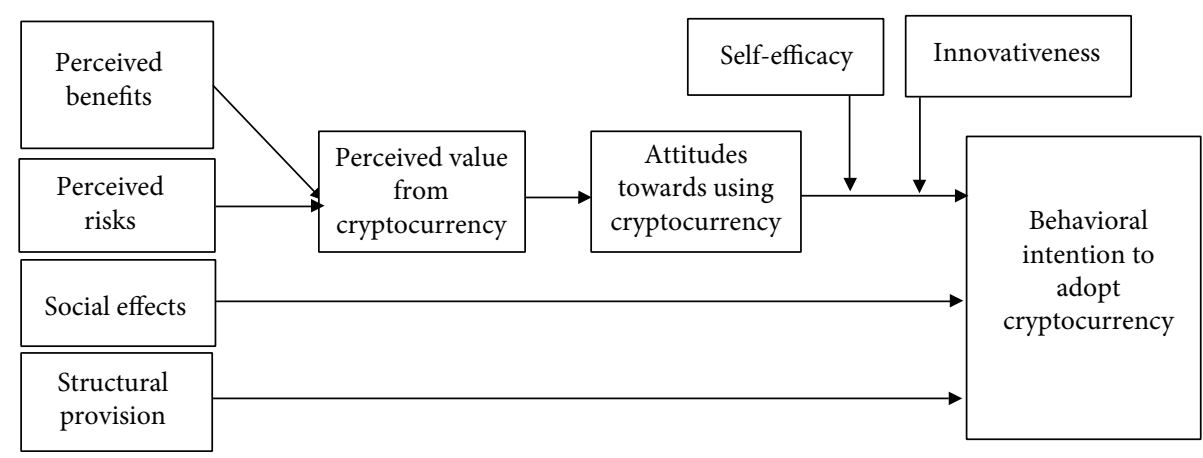

Figure 1: Proposed conceptual model.

TABLE 1: Research instruments.

\begin{tabular}{lccc}
\hline & Variables & Items & Sources \\
\hline 1 & Perceived benefits & 3 & {$[15]$} \\
2 & Perceived risks & 5 & {$[31] ;[24]$} \\
3 & Social effects & 3 & {$[26]$} \\
4 & Structural provisions & 4 & {$[26] ;[24]$} \\
5 & Perceived value from cryptocurrency & 4 & {$[44]$} \\
6 & Attitude towards cryptocurrency & 6 & {$[20] ;[15] ;[66]$} \\
7 & Self-efficacy & 3 & {$[67] ;[68]$} \\
8 & Personal innovativeness & 6 & {$[55]$} \\
9 & Behavioral intention to adopt cryptocurrency & 5 & {$[26] ;[20] ;[31] ;[66]$} \\
\hline
\end{tabular}

participants are 153 constituting the rest $43.7 \%$. The sample was largely composed of respondents of age between 20 and 25 years, i.e., 191 respondents (54.6\%). The qualification of the majority of respondents was bachelor's level (145 participants $(41.4 \%)$. The result reviews that most of our respondents $(42.86 \%)$ were receiving pocket money between 3,000 and 6,000 Rupees. Lastly, the result reveals that the majority of the participants belonged to the discipline of Computer \& IT, which is 108 respondents are constituting $30.86 \%$ of the total participants.

5.2. Pretest, Posttest Results. A pretest, posttest research was conducted to evaluate respondents' intention to adopt cryptocurrency before and after the awareness of cryptocurrency. This pretest, posttest research has been applied in various types of studies previously conducted, like by Rienties Brouwer and Lygo-Baker [69] to determine the intentions of teachers about technology and facilitation. Similarly, Lin [70] also conducted a pretest posttest study to measure the behavioral intention to adopt cryptocurrency. Table 3 shows descriptive statistics of pretest and posttest constructs by mean, standard deviation, kurtosis, and skewness, respectively. The mean difference between pre- and posttest is also indicated in Table 3, confirming the increase in mean values in posttest.

5.3. Paired Sample t-Test. Table 4 shows the paired sample $t$ -test that was conducted to determine the change in individual's perceptions about perceived benefits, risks and value of cryptocurrency, social effects, structural provisions, attitudes towards using cryptocurrency, and behavioral intention to adopt cryptocurrency before and after the intervention of video. As shown in Table 4, there is a significant increase in the perceived value of cryptocurrency $(M=3.79, \mathrm{SD}=$ .046) than before the video showcasing $(M=3.35, \mathrm{SD}=$ $.044) ; t(349)=8.86, p=.000$. Similarly, there is a significant increase in the perceived benefits after the video showcasing $(M=3.89, \mathrm{SD}=.049)$ than before the video showcasing $(M=3.45, \mathrm{SD}=.045) ; t(349)=8.97, p=.000$. Moreover, a significant increase has been observed in the perceived risks after the video showcasing $(M=3.73$, SD $=.042)$ than before the video showcasing $(M=3.57, \mathrm{SD}$ $=.041) ; t(349)=3.85, p=.000$. The social effects also indicated a significant increase after the video showcasing $(M=3.31, \mathrm{SD}=.056)$ than before the video showcasing $(M=3.24, \mathrm{SD}=.053) ; t(349)=1.76, p=.000$. The statistical values also show that there is a significant increase in the structural provisions after the video showcasing $(M=3.71, \mathrm{SD}=.048)$ than before the video showcasing $(M=3.01, \quad \mathrm{SD}=.046) ; t(349)=10.7, \quad p=.098$. Likewise, the attitude towards using cryptocurrency after the video showcasing $(M=3.76, \mathrm{SD}=.047)$ than before the video showcasing $(M=3.49, \mathrm{SD}=.047) ; t(349)=5.60, p=.000$, personal innovativeness after the video showcasing $(M=3.56, \mathrm{SD}=.049)$ than before the video showcasing $(M=3.48, \mathrm{SD}=.049) ; t(349)=2.33, p=.020$, self-efficacy after the video showcasing $(M=3.44, \mathrm{SD}=.057)$ than before the video showcasing $(M=3.28, \mathrm{SD}=.055)$; $t(349$ )$=3.13, p=.002$, and behavioral intention to adopt cryptocurrency after the video showcasing $(M=3.77, \mathrm{SD}=$ 
TABle 2: Demographic profile of respondents.

\begin{tabular}{|c|c|c|c|}
\hline Demographics & Categories & Frequencies & Percentage \\
\hline \multirow{3}{*}{ Gender } & Male & 197 & 56.3 \\
\hline & Female & 153 & 43.7 \\
\hline & Total & 350 & 100.0 \\
\hline \multirow{6}{*}{ Age } & Below 20 years & 35 & 10 \\
\hline & $20-25$ & 191 & 54.6 \\
\hline & $26-30$ & 93 & 26.6 \\
\hline & $31-35$ & 24 & 6.8 \\
\hline & 36 years and above & 7 & 2 \\
\hline & Total & 350 & 100.0 \\
\hline \multirow{5}{*}{ Qualification } & Bachelors & 145 & 41.4 \\
\hline & Masters & 100 & 28.6 \\
\hline & M. Phil & 94 & 26.9 \\
\hline & $\mathrm{PhD}$ & 11 & 3.1 \\
\hline & Total & 350 & 100.0 \\
\hline \multirow{5}{*}{ Monthly pocket money received (in rupee) } & Below 3,000 & 62 & 17.71 \\
\hline & $3,000-6,000$ & 150 & 42.86 \\
\hline & $6,100-9,000$ & 105 & 30 \\
\hline & Above 9,000 & 33 & 9.43 \\
\hline & Total & 350 & 100.0 \\
\hline \multirow{6}{*}{ Discipline } & Business Administration & 102 & 29.14 \\
\hline & Computer \& IT & 108 & 30.86 \\
\hline & Engineering & 70 & 20 \\
\hline & Environmental Sciences & 50 & 14.29 \\
\hline & Others & 20 & 5.71 \\
\hline & Total & 350 & 100.0 \\
\hline
\end{tabular}

TABle 3: Descriptive statistics of variables (pretest and posttest).

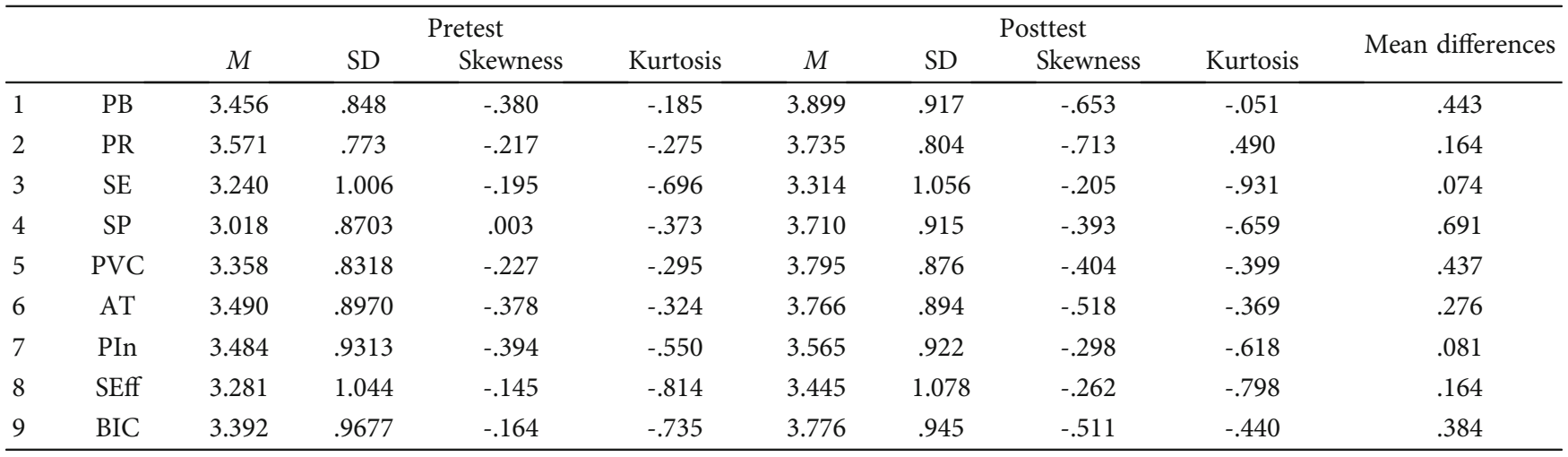

Note. PB: perceived benefits; PR: perceived risks; SE: social effects; SP: structural provisions; PVC: perceived value from cryptocurrency; AT: attitudes towards using cryptocurrency; PIn: personal innovativeness; SEff: self-efficacy; BIC: behavioral intention to adopt cryptocurrency.

.050) than before the video showcasing $(M=3.39, \mathrm{SD}=$ $.051) ; t(349)=6.73, p=.000$ confirmed a significant difference before and after video showcasing.

5.4. Correlation and Reliability Analysis. The values of Pearson correlation are depicted in Table 5 that indicate significant positive relationships among all variables. The highest value of correlation was found between attitude and struc- tural provision $(r=.845, p<.005)$, and the lowest value of correlation was found between the variables, social effects, and perceived risk $(r=.204, p<.005)$. In this research, the reliability analysis of the research variables was assessed by using Cronbach's Alpha. Cronbach's alpha values are also included in Table 5, confirming the reliability of the scale items used, i.e., all alpha values are above 0.6., mean and standard deviation values are also shown in Table 5. 
TABLe 4: Paired samples $t$-test.

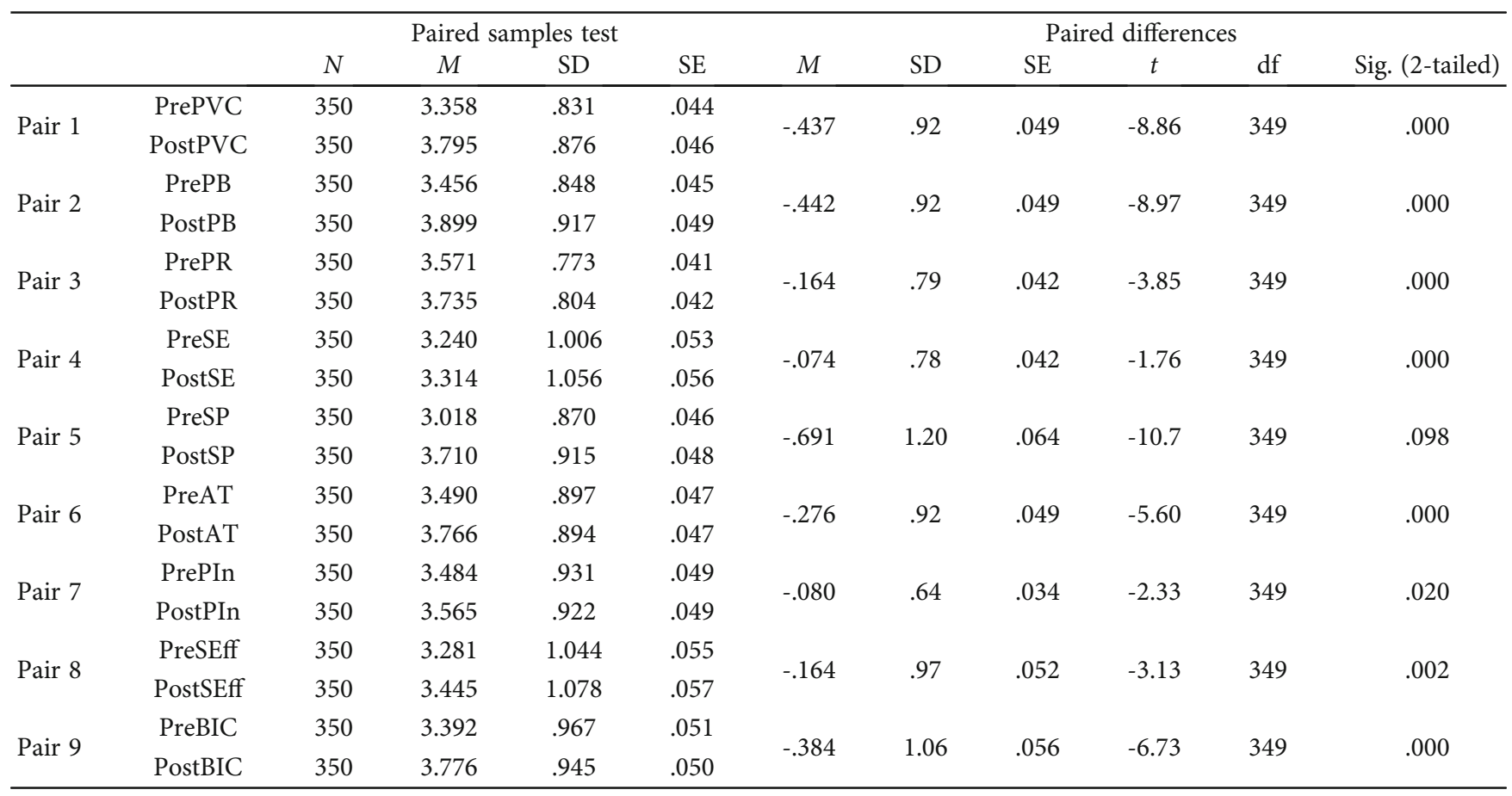

Note. PB: perceived benefits; PR: perceived risks; SE: social effects; SP: structural provisions; PVC: perceived value from cryptocurrency; AT: attitudes towards using cryptocurrency; PIn: personal innovativeness; SEff: self-efficacy; BIC: behavioral intention to adopt cryptocurrency.

TABLE 5: Correlation, mean, standard deviation, and Cronbach alpha.

\begin{tabular}{|c|c|c|c|c|c|c|c|c|c|c|c|c|c|}
\hline & & 1 & 2 & 3 & 4 & 5 & 6 & 7 & 8 & 9 & $\alpha$ & $M$ & $\mathrm{SD}$ \\
\hline 1 & $\mathrm{~PB}$ & - & & & & & & & & & .77 & 3.89 & .917 \\
\hline 2 & PR & $.391^{* *}$ & - & & & & & & & & .77 & 3.73 & .804 \\
\hline 3 & PVC & $.382^{* *}$ & $.258^{* *}$ & - & & & & & & & .82 & 3.31 & 1.05 \\
\hline 4 & SE & $.529^{* *}$ & $.204^{* *}$ & $.430^{* *}$ & - & & & & & & .81 & 3.71 & .915 \\
\hline 5 & SP & $.692^{* *}$ & $.337^{* *}$ & $.521^{* *}$ & $.693^{* *}$ & - & & & & & .80 & 3.79 & .876 \\
\hline 6 & $\mathrm{AT}$ & $.724^{* *}$ & $.356^{* *}$ & $.478^{* *}$ & $.649^{* *}$ & $.845^{* *}$ & - & & & & .88 & 3.76 & .894 \\
\hline 7 & PIn & $.520^{* *}$ & $.263^{* *}$ & $.384^{* *}$ & $.515^{* *}$ & $.658^{* *}$ & $.709^{* *}$ & - & & & .88 & 3.56 & .922 \\
\hline 8 & SEff & $.427^{* *}$ & $.226^{* *}$ & $.389^{* *}$ & $.484^{* *}$ & $.573^{* *}$ & $.635^{* *}$ & $.628^{* *}$ & - & & .68 & 3.44 & 1.07 \\
\hline 9 & BIC & $.629^{* *}$ & $.269^{* *}$ & $.441^{* *}$ & $.583^{* *}$ & $.743^{* *}$ & $.822^{* *}$ & $.724^{* *}$ & .816 & - & .88 & 3.77 & .945 \\
\hline
\end{tabular}

${ }^{* *}$ Correlation is significant at the 0.01 level (2-tailed). Note. PB: perceived benefits; PR: perceived risks; SE: social effects; SP: structural provisions; PVC: perceived value from cryptocurrency; AT: attitudes towards using cryptocurrency; SE: self-efficacy, PI: personal innovativeness; BIC: behavioral intention to adopt cryptocurrency.

5.5. Hypothesis Testing. Eight hypotheses have been developed; the hypothesis with linear relationships (H1(a), $\mathrm{H} 1$ (b) H2 (a), H2(b), H3, H4, and H5) were tested by conducting regression analysis. The moderated mediation hypotheses H6 (a), H6 (b), H7 (a), and H7 (b) were tested using process macromodel 14 by Preacher and Hayes. The statistical values in Table 6 present regression analysis that was conducted to examine the effect of independent variables on dependent variables. In the first step, the variable, perceived benefits was regressed upon the perceived value from cryptocurrency. The results show that perceived benefits have a significant positive effect on perceived value from cryptocurrency $\left(\beta=.692, t=17.876, p=.000, R^{2}=0.479, F\right.$
$=319.536, \mathrm{df}=(1,348))$. Thus, $\mathrm{H1}(\mathrm{a})$ was accepted. In hypothesis ( $1 \mathrm{~b})$, it was assumed that perceived benefits have a positive effect on behavioral intention to use cryptocurrency. The statistical values $(\beta=.194, t=3.639, p=.000$, $R^{2}=0.613, \quad F=108.801, \quad \mathrm{df}=(5,344) \quad$ confirmed this assumption. Therefore, H1(b) was accepted.

In another step, perceived risk was regressed upon the perceived value from cryptocurrency. The values $(\beta=.337$, $t=6.668, \quad p<.01, \quad R^{2}=0.113, \quad F=44.467, \quad \mathrm{df}=(1,348)$ showed a positive influence of perceived risk on perceived value from cryptocurrency. Thus, H2 (a) was not accepted. When the effect of perceived risk was checked on behavior intention, it was revealed that perceived risk $(\beta=-.077, t$ 
TABLE 6: Hypotheses testing.

\begin{tabular}{|c|c|c|c|c|c|c|c|}
\hline & Predictors & $\beta$ & $t$ & Sig & $R^{2}$ & $F$ & $\mathrm{df}$ \\
\hline H1 (a) & Perceived benefits $\longrightarrow$ perceived value & .692 & 17.87 & .000 & 0.479 & 319.53 & $(1,348)$ \\
\hline H1 (b) & Perceived benefits $\longrightarrow$ behavioral intention & .194 & 3.63 & .000 & 0.613 & 108.80 & $(5,344)$ \\
\hline $\mathrm{H} 2$ (a) & Perceived risk $\longrightarrow$ perceived value & .337 & 6.66 & .000 & 0.113 & 44.46 & $(1,348)$ \\
\hline $\mathrm{H} 2$ (b) & Perceived risk $\longrightarrow$ behavioral intention to use cryptocurrency & -.077 & -1.912 & .057 & & & \\
\hline $\mathrm{H} 3$ & Perceived value $\longrightarrow$ attitudes towards using cryptocurrency & .845 & 29.48 & .000 & 0.714 & 869.37 & $(1,348)$ \\
\hline $\mathrm{H} 4$ & Social effects $\longrightarrow$ behavioral intention to use cryptocurrency & .024 & .651 & .516 & & & \\
\hline H5 & Structural provision $\longrightarrow$ behavioral intention to use cryptocurrency & .142 & 2.794 & .005 & & & \\
\hline
\end{tabular}

$=-1.912, p<.01, R^{2}=.057, F=108.801, \mathrm{df}=(5,344)$ has a significant negative effect on behavior intention to adopt cryptocurrency. Thus, H2 (b) was accepted.

In a subsequent step, the positive impact of perceived value from cryptocurrency on attitudes towards using cryptocurrency was checked. The statistical values $(\beta=.845, t$ $=29.485, p<.01, R^{2}=0.714, F=869.372$, df $=(1,348)$ confirmed the significant positive impact of perceived value from cryptocurrency on attitudes towards using cryptocurrency. So, H3 was accepted.

The other variables like social effects $(\beta=.024, t=-.651$, $p>.05, R^{2}=.057, F=108.801, \mathrm{df}=(5,344)$, on behavioral intention to use cryptocurrency yielded insignificant results. Hence, $\mathrm{H} 4$ was rejected. The impact of structural provision $\left(\beta=.142, t=2.794, p=.005, R^{2}=.057, F=108.801, \mathrm{df}=(5\right.$ $, 344)$ on behavioral intention to use cryptocurrency confirmed a positive significant result. Therefore, $\mathrm{H} 5$ was accepted.

5.6. Moderated Mediation Analysis. To investigate the moderation effects, a moderation mediation analysis was performed by using process macro model 14 by Preacher and Hayes. The results are shown in Table 7 which indicate that the independent variable perceived value from cryptocurrency has a positive significant impact on the mediator variable attitudes towards using cryptocurrency $(\beta=0.86$, $\mathrm{SE}=0.02,95 \% \mathrm{CI}=[0.80,0.91])$ and also on the dependent variable behavioral intention to use cryptocurrency $(\beta=0.35, \mathrm{SE}=0.08, \quad 95 \% \mathrm{CI}=[0.19,0.51])$. Furthermore, the mediator variable attitudes towards using cryptocurrency also has a positive significant impact on the dependent variable behavioral intention to use cryptocurrency $(\beta=0.47$ , $\mathrm{SE}=0.08,95 \% \mathrm{CI}=[0.31,0.64])$. Similarly, the moderator variable self-efficacy has a positive significant impact on dependent variable behavioral intention to use cryptocurrency $(\beta=0.09, \mathrm{SE}=0.04,95 \% \mathrm{CI}=[0.01,0.17])$. However, the interaction or moderating effect $(M \times W)$ shows that the moderating effect is not significant, as there is a negative and positive interval $(\beta=-0.03, \mathrm{SE}=0.04,95 \% \mathrm{CI}=[-0.11$ , 0.05]). So, hypothesis 6 (a) is rejected. Table 7 also shows the index of moderated mediation in which the index is negative and close to zero (-.0308); also, the lower and upper limits of the confidence interval are opposite in direction. It indicates that the mediation is not significant upon the level of moderator. Therefore, hypothesis 7 (a) is rejected.

The moderated mediation of personal innovativeness was also tested by using the PROCESS macromodel 14 of
Preacher and Hayes. The results are shown in Table 8 which indicate that the independent variable perceived value from cryptocurrency has a positive significant impact on the mediator variable attitudes towards using cryptocurrency $(\beta=0.86, \mathrm{SE}=0.02,95 \% \mathrm{CI}=[0.80,0.91])$ and also on the dependent variable behavioural intention to use cryptocurrency $(\beta=0.33, \mathrm{SE}=0.07,95 \% \mathrm{CI}=[0.18,0.48])$. Furthermore, the mediator variable attitudes towards using cryptocurrency also has a positive significant impact on the dependent variable behavioural intention to use cryptocurrency $(\beta=0.43, \mathrm{SE}=0.08,95 \% \mathrm{CI}=[0.27,0.59])$.

Similarly, the moderator variable (as shown in Table 8), personal innovativeness, has a positive significant impact on dependent variable behavioural intention to use cryptocurrency $(\beta=0.16, \mathrm{SE}=0.05,95 \% \mathrm{CI}=[0.06,0.27])$. However, the interaction or moderating effect $(M \times W)$ shows that the moderating effect of personal innovativeness is not significant, as there is a negative and positive interval $(\beta=-0.07, \mathrm{SE}=0.04,95 \% \mathrm{CI}=[-0.16,0.01])$. So, hypothesis 6 (b) is rejected. Table 8 also shows the index of moderated mediation in which the index is negative and close to zero (-.0639); also, the lower and upper limits of the confidence interval are opposite in direction. It indicates that the mediation is not significant upon the level of moderator. Therefore, hypothesis 7 (b) is also rejected.

\section{Discussion}

This study is aimed at investigating individual's intention to use cryptocurrency. The cryptocurrency is not legally in use in the selected country of study; hence, before conducting the survey, a video showcasing was used. The purpose was to create awareness of cryptocurrency among the study participants. To gauge the effectiveness of video showcasing, pre and posttest were also conducted. The statistical results of the paired sample $t$-test confirmed that the study participants' level of awareness about different aspects of cryptocurrency was increased after showing the informative videos, and they were better able to reveal their opinions about the cryptocurrency. From methodology point of view, this was a one-of-a-kind attempt to ensure participants' awareness to avoid any potential threat of lack of awareness.

The findings of hypotheses 1 (a) and 1 (b) of the current research revealed that perceived benefits of cryptocurrency enhance its perceived values as well as the behavioral intention to use cryptocurrency. The findings are in line with the findings of previous studies [13-15, 71]. The findings 
TABle 7: Moderated mediation analysis (self-efficacy).

\begin{tabular}{|c|c|c|c|c|c|c|}
\hline \multirow[b]{2}{*}{ Model } & \multicolumn{3}{|c|}{$\begin{array}{l}\text { Attitudes towards using cryptocurrency } \\
\qquad(\mathrm{M})\end{array}$} & \multicolumn{3}{|c|}{$\begin{array}{l}\text { Behavioral intention to use } \\
\text { cryptocurrency (DV) }\end{array}$} \\
\hline & $\beta$ & SE & $\begin{array}{c}95 \% \text { CI } \\
\text { LLCI (ULCI) }\end{array}$ & $\beta$ & SE & $\begin{array}{c}95 \% \text { CI } \\
\text { LLCI (ULCI) }\end{array}$ \\
\hline Constant & -3.2647 & .1142 & $-3.4893(-3.0402)$ & 2.4441 & .3137 & $1.8272(3.0610)$ \\
\hline Perceived value from cryptocurrency (IV) & .8601 & .0271 & $.8068(.9134)$ & .3555 & .0816 & $.1961(.5160)$ \\
\hline Attitudes towards using cryptocurrency (M) & & & & .4718 & .0847 & $.3051(.6385)$ \\
\hline Self-efficacy (W) & & & & .0928 & .0408 & $.0126(.1731)$ \\
\hline \multirow[t]{4}{*}{$M \times W$} & & & & -.0359 & .0422 & $-.1189(.0472)$ \\
\hline & $R^{2}$ & & 0.71 & $R^{2}$ & & 0.66 \\
\hline & $F(\mathrm{df})$ & $F(1$, & $\begin{array}{l}=1006.83, p< \\
.0000\end{array}$ & $F(\mathrm{df})$ & $F(4,3$ & $\begin{array}{l}=137.50, p< \\
.0000\end{array}$ \\
\hline & Index & & BootSE & BootLLCI & & BootULCI \\
\hline Self-efficacy & -.0308 & & .0330 & -.0868 & & .0428 \\
\hline
\end{tabular}

TABLE 8: Moderated mediation analysis (personal innovativeness).

\begin{tabular}{|c|c|c|c|c|c|c|}
\hline \multirow{3}{*}{ Model } & \multicolumn{3}{|c|}{$\begin{array}{l}\text { Attitudes towards using } \\
\text { cryptocurrency (M) }\end{array}$} & \multicolumn{3}{|c|}{$\begin{array}{l}\text { Behavioral intention to use } \\
\text { cryptocurrency (DV) }\end{array}$} \\
\hline & $\beta$ & $\mathrm{SF}$ & $95 \% \mathrm{CI}$ & $\beta$ & SE & $95 \% \mathrm{CI}$ \\
\hline & $\mathcal{\beta}$ & SE & LLCI (ULCI) & $\mathcal{\beta}$ & $\mathrm{SE}$ & LLCI (ULCI) \\
\hline Constant & -3.264 & .114 & $-3.489(-3.0402)$ & 2.548 & .298 & $1.961(3.1345)$ \\
\hline Perceived value from cryptocurrency (IV) & .860 & .027 & $.806(.9134)$ & .333 & .077 & $.181(.4856)$ \\
\hline Attitudes towards using cryptocurrency (M) & & & & .431 & .080 & $.272(.5898)$ \\
\hline Personal innovativeness (W) & & & & .164 & .052 & $.060(.2681)$ \\
\hline \multirow[t]{4}{*}{$M \times W$} & & & & -.074 & .042 & $-.158(.0097)$ \\
\hline & $R^{2}$ & & 0.71 & $R^{2}$ & & 0.67 \\
\hline & $F(\mathrm{df})$ & $F(1$ & $\begin{array}{l}=1006.83, p< \\
.0000\end{array}$ & $F(\mathrm{df})$ & $F(4$, & $\begin{array}{l}=139.23, p< \\
.0000\end{array}$ \\
\hline & Index & & Boot SE & Boot LLCI & & oot ULCI \\
\hline Personal innovativeness & -.0639 & & .0327 & -.1235 & & .0064 \\
\hline
\end{tabular}

suggest that users' intention to use cryptocurrency currency can be heightened if the perceived benefits and perceived value of the currency are effectively conveyed to users.

The findings of hypotheses 2 (a) and 2 (b) of the study confirmed that the negative effect of perceived risks on perceived value from cryptocurrency was not proven. However, a significant negative impact of perceived risks on behavioral intention was confirmed. Because users are apprehensive about the risk issues linked with cryptocurrencies, there is a negative relationship between perceived risks and behavioural intention to use cryptocurrency. The cryptocurrency involves risky transactions and many security concerns; therefore, the perceived high risk would discourage users to use or adopt it. The finding of this research is consistent with the findings of previous studies of Kazi and Mannan [42] and Abramova and Böhme [13].

The findings of hypothesis 3 of this study show that perceived value has significant positive impacts on attitudes towards using cryptocurrency. The positive significant association arises from the fact that cryptocurrency is a new phe- nomenon for Pakistani people, and their attitude is influenced by the value they place on it. The higher the perceived value, the higher will be the positive attitude towards adoption. This finding is similar to the findings of previous studies of Farah et al. [50], Pitchayadejanant [49], and Liu et al. [48].

In the study, hypothesis 4 produced the insignificant impact of social effects on behavioral intention to use cryptocurrency. As cryptocurrency is not currently in use in the country, hence, social effects could be ruled out. If this technology is widely used, the social impact may be more pronounced. The other possible explanation could be that cryptocurrency involves a major financial decision process, for which opinions from the social circle do not have the effect [59]. This finding is similar to the findings of Abbasi et al. [59] and Arias-Oliva et al. [26].

The statistical results of hypothesis 5 confirmed the significant positive impact of structural provisions on behavioral intention to use cryptocurrency. This means that if all requirements, facilities, and infrastructure are provided to 
users, then their adoption rate of cryptocurrency would be high. These findings are consistent with the findings of previous studies (e.g. [24, 26, 72]).

In the analysis, moderated mediation analysis was also done. The findings of hypotheses 6 (a) and 6 (b) of this research revealed that both personality traits, i.e., selfefficacy and personal innovativeness, do not have any moderating effect on the mediated path of attitude towards using cryptocurrency and behavioral intention to use cryptocurrency. The explanation for this could be that users do not use cryptocurrency. Therefore, without actual usage of the technology, personality traits like self-efficacy and personal innovativeness as a moderator could not yield the desired results. On the other hand, a significant positive impact of self-efficacy and personal innovativeness on behavioral intention to use cryptocurrency was evident which supports the findings of previous studies $[4,53]$.

Findings of hypothesis 7 of the study revealed that attitude does not have a mediating effect, through the moderated mediation model, on behavioral intention to use cryptocurrency. However, the mediator variable attitudes towards using cryptocurrency have a positive significant effect on the outcome variable behavioral intention to use cryptocurrency which is consistent with the findings of previous research $[15,20,63,64]$.

6.1. Implications. On the recommendation of a study by Esmaeilzadeh et al. [16], this research tried to empirically validate an IT model to investigate constructs to adopt the cryptocurrency. Cryptocurrency is different from other technologies because it has financial aspects, legal issues, and risks. Therefore, a comprehensive model consisting of socio-technical factors was appropriate to give a holistic view of the adoption of cryptocurrency. Hence, this research has filled a gap in the application of an extended model to the cryptocurrency framework. This research contributes to the literature by empirically investigating the factors that impact the intention of individuals to use cryptocurrency. So, this research provides a better understanding and theoretical base to future researchers about individuals' perceptions to use cryptocurrency.

Furthermore, by analyzing the moderating influence of personal innovativeness and self-efficacy, the current study added to the body of existing knowledge. The empirical investigation of novel relationships in the context of cryptocurrency adoption that were not or less studied in previous research allows scholars to gain a better understanding of the elements that influence the adoption of new technology, especially in a developing country context.

The study has a productive contribution to research methodology, as, it has used a video showcasing approach to create awareness among participants about the cryptocurrency. This can be a novel base for further studies as a piece of research equipment to create familiarity about a phenomenon. The findings of this study have improved the understanding of individual adoption factors of cryptocurrency. This could be helpful for practitioners to implement certain strategies for introducing cryptocurrency in the country by understating user's intentions factors. The adoption of cryp- tocurrency technology will be impossible unless users accept it as a viable alternative to traditional payment methods.

The findings of this study will help service providers build ways to encourage customers to utilize cryptocurrencies in their daily lives by emphasizing how to make the process of utilizing cryptocurrency more beneficial, easy, fun, and trustworthy. The findings are particularly significant in developing country contexts that are lagging in adopting cryptocurrency. From a managerial perspective, the findings of this study are anticipated to widely contribute to the government, policymakers, and higher authorities to lift the ban on virtual currencies, introduce regulations to regulate and monitor cryptocurrencies in Pakistan, and issue its cryptocurrency. Local financial institutions and regulators might both illustrate the benefits of cryptocurrency use to boost country's adoption rate. Software engineers could also gain some insights from this research as they design and manage cryptocurrency applications by making them more valuable.

6.2. Limitations. This study has some limitations. First, the study was conducted online due to the COVID-19 pandemic and focused only on students that may limit the generalization of findings. Secondly, this study adopted a moderated mediation model which ignores other important constructs such as effort expectancy, performance expectancy, hedonic motivation, and price volatility of cryptocurrency which may have a significant impact on an individual's intention to adopt cryptocurrency. So, future researchers can focus on these limitations by conducting further research. The study was cross-sectional in nature that does not count the behavioral changes over time. Therefore, future studies could use longitudinal studies to appreciate the evolving factors that may influence a user's willingness to adopt cryptocurrencies.

\section{Conclusion}

Cryptocurrency is in vogue, and therefore, requires some deeper understanding of factors of its adoption both at the individual and organizational level. The current study is aimed at investigating cryptocurrency at the individual level to provide a comprehensive understanding of factors of the adoption of cryptocurrency. As the currency was not in actual use in the study settings, therefore, a video showcasing approach was used to create awareness among the participants. The framework consisting of many constructs exhibited strong support for perceived benefits, perceived risks, perceived value, and structural provisions for the adoption of cryptocurrency among individuals. In case the country decides to adopt this new digital economic tool, the research shows that it would gain acceptance by the public. Thus, policymakers should adopt an approach for the adoption of this emerging financial technology by addressing the facilitating conditions, incorporating benefits, and highlighting the values of cryptocurrency as evident by this study. The study can be taken as a recommendation to policymakers and higher authorities to lift the ban on cryptocurrencies by regulating it properly and also spreading awareness among people to avoid any financial losses. 


\section{Data Availability}

Data is available on request and can be requested by sending an email to the author: huma_ayub@fjwu.edu.pk.

\section{Conflicts of Interest}

The authors declare that they have no conflicts of interest.

\section{Supplementary Materials}

Table: research instruments. (Supplementary Materials)

\section{References}

[1] F. Duma and R. Gligor, "Study regarding Romanian students' perception and behaviour concerning the Fintech area with a focus on cryptocurrencies and online payments," Online Journal Modelling the New Europe, vol. 27, no. 27, pp. 86-106, 2018.

[2] M. Shoaib, M. Ilyas, and M. S. H. Khiyal, "Official digital currency," in Eighth International Conference on Digital Information Management (ICDIM 2013), pp. 346-352, Islamabad, Pakistan, 2013, September.

[3] A. Narayanan and J. Clark, "Bitcoin's academic pedigree," Communications of the ACM, vol. 60, no. 12, pp. 36-45, 2017.

[4] F. Sudzina and A. Pavlicek, "Impact of personality traits (BFI2-XS) on use of cryptocurrencies," in Proceedings of the International Scientific Conference Hradec Economic Days 2019 Part II, pp. 363-369, Hradec Králové, 2019.

[5] CoinMarketCap, "Cryptocurrency Market Capitalizations," 2020, https://coinmarketcap.com/.

[6] E. F. Churchill, "Why should we care about bitcoin?," Interactions, vol. 22, no. 5, pp. 20-21, 2015.

[7] G. R. White, "Future applications of blockchain in business and management: a Delphi study," Strategic Change, vol. 26, no. 5, pp. 439-451, 2017.

[8] M. I. Sarwar, K. Nisar, and A. Khan, "Blockchain-from cryptocurrency to vertical industries-a deep shift," in 2019 IEEE International Conference on Signal Processing, Communications and Computing (ICSPCC), pp. 1-4, Dalian, China, 2019, September.

[9] State Bank of Pakistan, "Soundness and efficiency of financial market infrastructure," in Financial Stability Review (Chap. 5), 2016, https://www.sbp.org.pk/FSR/2016/pdf/FSR-2016Complete.pdf.

[10] A. Afzal and A. Asif, "Cryptocurrencies, blockchain, and regulation: a review," The Lahore Journal of Economics, vol. 24, no. 1, pp. 103-130, 2019.

[11] S. A. Ibrahim, "Regulating cryptocurrencies to combat terrorism-financing and money laundering," Stratagem, vol. 2, no. 1, 2019.

[12] O. Alqaryouti, N. Siyam, Z. Alkashri, and K. Shaalan, "Cryptocurrency usage impact on perceived benefits and users' behaviour," in European, Mediterranean, and Middle Eastern Conference on Information Systems, vol. 381, pp. 123-136, European, Mediterranean, and Middle Eastern, 2019.

[13] S. Abramova and R. Böhme, "Perceived benefit and risk as multidimensional determinants of bitcoin use: a quantitative exploratory study," in 2016 International Conference on Information Systems, ICIS 2016, pp. 1-20, Zohar, 2016.
[14] H. M. Gazali, C. M. H. B. C. Ismail, and T. Amboala, "Exploring the intention to invest in cryptocurrency: the case of bitcoin," in Proceedings - International Conference on Information and Communication Technology for the Muslim World 2018, ICT4M 2018, pp. 64-68, Kuala Lumpur, Malaysia, 2018, July.

[15] A. Walch, "The bitcoin blockchain as financial market infrastructure: a consideration of operational risk'(2015)," NYU Journal of Legislation and Public Policy, vol. 18, no. 4, p. 837, 2015.

[16] P. Esmaeilzadeh, H. Subramanian, and K. Cousins, "Individuals' cryptocurrency adoption: a proposed moderatedmediation model," in 25th Americas Conference on Information Systems, AMCIS 2019, pp. 1-10, Cancún, Mexico, 2019.

[17] S. Bibi, S. Hussain, and M. I. Faisal, "Public Perception Based Recommendation System for Cryptocurrency," in 2019 16th International Bhurban Conference on Applied Sciences and Technology (IBCAST), pp. 661-665, Islamabad, Pakistan, 2019.

[18] E. M. Rogers, Diffusion of innovations, Simon and Schuster, 2010.

[19] P. Sheeran, A. Maki, E. Montanaro et al., "The impact of changing attitudes, norms, and self-efficacy on health-related intentions and behavior: a meta-analysis," Health Psychology, vol. 35, no. 11, pp. 1178-1188, 2016.

[20] L. C. Schaupp and M. Festa, "Cryptocurrency adoption and the road to regulation," in ACM International Conference Proceeding Series, pp. 1-9, Delft, The Netherlands, 2018.

[21] A. Alshamsi and P. P. Andras, "User perception of bitcoin usability and security across novice users," International Journal of Human-Computer Studies, vol. 126, pp. 94-110, 2019.

[22] G. Thapar and P. Chandel, "Bitcoin : the crypto currency and the dark web," SSRG International Journal of Computer Science and Engineering (SSRG - IJCSE), vol. 5, no. 8, pp. 6-7, 2018.

[23] C. C. Lee, J. C. Kriscenski, and H. S. Lim, "An empirical study of behavioral intention to use blockchain technology," Journal of International Business Disciplines, vol. 14, no. 1, pp. 1-21, 2019.

[24] K. H. Chan, S. M. Chiew, J. Y. Chong, P. Y. Foong, and L. X. Zhen, Acceptance of Cryptocurrency among Ipoh Residents (Doctoral dissertation), UTAR, 2018.

[25] Y. Y. Chow, K. S. Kalid, and S. K. Sugathan, "Cryptocurrency acceptance: a case of Malaysia," International Journal of Engineering and Advanced Technology, vol. 8, no. 5, pp. 28-38, 2019.

[26] M. Arias-Oliva, J. Pelegrín-Borondo, and G. Matías-Clavero, "Variables influencing cryptocurrency use: a technology acceptance model in Spain," Frontiers in Psychology, vol. 10, p. $475,2019$.

[27] O. Bondarenko, O. Kichuk, and A. Antonov, "The possibilities of using investment tools based on cryptocurrency in the development of the national economy," Baltic Journal of Economic Studies, vol. 5, no. 2, pp. 10-17, 2019.

[28] M. A. Nadeem, Z. Liu, A. H. Pitafi, A. Younis, and Y. Xu, "Investigating the adoption factors of cryptocurrencies-a case of bitcoin: empirical evidence from China," SAGE Open, vol. 11, no. 1, p. 215824402199870, 2021.

[29] A. Walton and K. Johnston, "Exploring perceptions of bitcoin adoption: the south African virtual community perspective," Interdisciplinary Journal of Information, Knowledge, and Management, vol. 13, pp. 165-182, 2018. 
[30] J. C. Mendoza-Tello, H. Mora, F. A. Pujol-López, and M. D. Lytras, "Social commerce as a driver to enhance trust and intention to use cryptocurrencies for electronic payments," IEEE Access, vol. 6, pp. 50737-50751, 2018.

[31] J. C. Mendoza-Tello, H. Mora, F. A. Pujol-López, and M. D. Lytras, "Disruptive innovation of cryptocurrencies in consumer acceptance and trust," Information Systems and eBusiness Management, vol. 17, no. 2-4, pp. 195-222, 2019.

[32] T. Aste, "Cryptocurrency market structure: connecting emotions and economics," Digital Finance, vol. 1, no. 1-4, pp. 521, 2019.

[33] G. P. Dwyer, "The economics of bitcoin and similar private digital currencies," Journal of Financial Stability, vol. 17, pp. 81-91, 2015.

[34] X. Hua, Y. Huang, and Y. Zheng, "Current practices, new insights, and emerging trends of financial technologies," Industrial Management \& Data Systems, vol. 119, no. 7, pp. 1401-1410, 2019.

[35] J. Liu and A. Serletis, "Volatility in the cryptocurrency market," Open Economies Review, vol. 30, no. 4, pp. 779-811, 2019.

[36] E. Pichet, Bitcoin: speculative bubble or future value?, vol. 28, The Conversation (French edition), 2017.

[37] V. Venkatesh, M. G. Morris, G. B. Davis, and F. D. Davis, "User acceptance of information technology: toward a unified view," MIS Quarterly, vol. 27, no. 3, pp. 425-478, 2003.

[38] X. Gao, G. D. Clark, and J. Lindqvist, "Of two minds, multiple addresses, and one history: characterizing opinions, knowledge, and perceptions of bitcoin across groups," 2015, https://arxiv.org/abs/1503.02377.

[39] A. S. Irwin and A. B. Turner, "Illicit bitcoin transactions: challenges in getting to the who, what, when and where," Journal of Money Laundering Control, vol. 21, no. 3, pp. 297-313, 2018.

[40] M. Y. Yi, K. D. Fiedler, and J. S. Park, "Understanding the role of individual innovativeness in the acceptance of IT-based innovations: comparative analyses of models and measures," Decision Sciences, vol. 37, no. 3, pp. 393-426, 2006.

[41] E. D. Zamani and I. Babatsikos, "The Use of Bitcoins in Light of the Financial Crisis: the Case of Greece," in 11th Mediterranean Conference on Information Systems (MCIS), Genoa, Italy, 2017.

[42] A. K. Kazi and M. A. Mannan, "Factors affecting adoption of mobile banking in Pakistan," International Journal of Research in Business and Social Science (2147-4478), vol. 2, no. 3, pp. 5461, 2013.

[43] N. Parashar and F. Rasiwala, “A study on investor' s awareness and perception regarding investment in crypto currency with special reference to bitcoin," International Journal of Scientific and Research Publications, vol. 8, no. 12, pp. 311-319, 2018.

[44] H. W. Kim, H. C. Chan, and S. Gupta, "Value-based adoption of mobile Internet: an empirical investigation," Decision Support Systems, vol. 43, no. 1, pp. 111-126, 2007.

[45] T.-T. T. Pham and J. C. Ho, "The effects of product-related, personal-related factors and attractiveness of alternatives on consumer adoption of NFC-based mobile payments," Technology in society, vol. 43, pp. 159-172, 2015.

[46] H. Xu and S. Gupta, "The effects of privacy concerns and personal innovativeness on potential and experienced customers' adoption of location-based services," Electronic Markets, vol. 19, no. 2-3, pp. 137-149, 2009.

[47] S. Alaklabi and K. Kang, "Factors influencing behavioral intention to adopt blockchain technology," in Proceedings of the 32nd International Business Information Management Association Conference, IBIMA 2018 - Vision 2020: Sustainable Economic Development and Application of Innovation Management from Regional Expansion to Global Growth, pp. 5170-5174, Seville, Spain, 2018.

[48] F. Liu, X. Zhao, P. Y. K. Chau, and Q. Tang, "Roles of perceived value and individual differences in the acceptance of mobile coupon applications," Internet Research, vol. 25, no. 3, pp. 471-495, 2015.

[49] K. Pitchayadejanant, "Intention to use of smart phone in Bangkok extended UTAUT model by perceived value," in International Conference on Management (ICM 2011) Proceeding. Conference Master Resources, Penang, Malaysia, 2011.

[50] M. F. Farah, M. J. S. Hasni, and A. K. Abbas, "Mobile-banking adoption: empirical evidence from the banking sector in Pakistan," International Journal of Bank Marketing, vol. 36, no. 7, pp. 1386-1413, 2018.

[51] M. Mainelli and M. Smith, "Sharing ledgers for sharing economies: an exploration of mutual distributed ledgers (aka blockchain technology)," Journal of Financial Perspectives, vol. 3, no. 3, 2015.

[52] A. R. Alenezi and A. Karim, "An empirical investigation into the role of enjoyment, computer anxiety, computer selfefficacy and internet experience in influencing the students' intention to use e-learning: A case study from Saudi Arabian governmental universities," Turkish Online Journal of Educational Technology-TOJET, vol. 9, no. 4, pp. 22-34, 2010.

[53] I. Almarashdeh, "An overview of technology evolution : investigating the factors influencing non- bitcoins users to adopt bitcoins as an online payment transaction method," Journal of Theoretical and Applied Information Technology, vol. 96, no. 13, pp. 3984-3993, 2018.

[54] F. Shahzad, G. Y. Xiu, J. Wang, and M. Shahbaz, “An empirical investigation on the adoption of cryptocurrencies among the people of mainland China," Technology in Society, vol. 55, pp. 33-40, 2018.

[55] A. Baabdullah, Y. Dwivedi, M. Williams, and P. Kumar, "Understanding the Adoption of Mobile Internet in the Saudi Arabian Context: Results from the Descriptive Analysis," in Conference on e-Business, e-Services and e-Society, pp. 95106, Delft, The Netherlands, 2015.

[56] R. Agarwal and J. Prasad, "A conceptual and operational definition of personal innovativeness in the domain of information technology," Information Systems Research, vol. 9, no. 2, pp. 204-215, 1998.

[57] H. Yang, J. Yu, H. Zo, and M. Choi, "User acceptance of wearable devices: an extended perspective of perceived value," Telematics and Informatics, vol. 33, no. 2, pp. 256-269, 2016.

[58] World Economic Forum, "Deep Shift: Technology Tipping Points and Societal Impact," World Economic Forum, Cologny, Geneva, Switzerland, 2015.

[59] G. A. Abbasi, L. Y. Tiew, J. Tang, Y. N. Goh, and R. Thurasamy, "The adoption of cryptocurrency as a disruptive force: deep learning-based dual stage structural equation modelling and artificial neural network analysis," PLoS One, vol. 16, no. 3, article e0247582, 2021.

[60] A. Nazifi, S. Murdy, B. Marder, J. Gäthke, and B. Shabani, “A bit(coin) of happiness after a failure: an empirical examination of the effectiveness of cryptocurrencies as an innovative recovery tool," Journal of Business Research, vol. 124, pp. 494-505, 2021. 
[61] Y. K. Lee, "Impacts of digital technostress and digital technology self-efficacy on Fintech usage intention of Chinese Gen Z consumers," Sustainability, vol. 13, no. 9, p. 5077, 2021.

[62] M. Fishbein and I. Ajzen, "Belief, Attitude, Intention, and Behavior: An Introduction to Theory and Research," Philosophy and Rhetoric, vol. 10, no. 2, 1977.

[63] S. A. Mosavi and M. Ghaedi, "An examination of the effects of perceived value and attitude on customers' behavioral intentions in e- shopping," African Journal of Business Management, vol. 6, no. 5, pp. 1950-1959, 2012.

[64] F. Mazhar, M. Rizwan, U. Fiaz, S. Ishrat, M. S. Razzaq, and T. N. Khan, "An investigation of factors affecting usage and adoption of internet \& mobile banking in Pakistan," International Journal of Accounting and Financial Reporting, vol. 4, no. 2, p. 478, 2014.

[65] A. A. Khan, M. Ilyas, and C. Abdul Rehman, "Generation (Z) is coming, are you ready?: a wakeup call for HR strategists in Pakistan," Review of Public Administration and Management, vol. 400, no. 4289, pp. 1-12, 2016.

[66] O. Alaeddin and R. Altounjy, "Trust, technology awareness and satisfaction effect into the intention to use cryptocurrency among generation $\mathrm{Z}$ in Malaysia," International Journal of Engineering \& Technology, vol. 7, no. 4.29, pp. 8-10, 2018.

[67] J. Lu, J. E. Yao, and C. S. Yu, "Personal innovativeness, social influences and adoption of wireless Internet services via mobile technology," The Journal of Strategic Information Systems, vol. 14, no. 3, pp. 245-268, 2005.

[68] I. M. Al-Jabri, "The intention to use mobile banking: further evidence from Saudi Arabia," South African Journal of Business Management, vol. 46, no. 1, pp. 23-34, 2015.

[69] B. Rienties, N. Brouwer, and S. Lygo-Baker, "The effects of online professional development on higher education teachers' beliefs and intentions towards learning facilitation and technology," Teaching and Teacher Education, vol. 29, pp. 122131, 2013.

[70] H. F. Lin, "Understanding behavioral intention to participate in virtual communities," Cyber Psychology \& Behavior, vol. 9, no. 5, pp. 540-547, 2006.

[71] A. Bhatti and S. U. Rehman, "Perceived benefits and perceived risks effect on online shopping behavior with the mediating role of consumer purchase intention in Pakistan," International Journal of Management Studies, vol. 26, no. 1, pp. 33$54,2020$.

[72] Y. K. Dwivedi, K. Khoumbati, M. D. Williams, and B. Lal, "Factors affecting consumers' behavioural intention to adopt broadband in Pakistan," Transforming Government: People, Process and Policy, vol. 1, no. 3, pp. 285-297, 2007. 